\title{
An Analysis of Somatic Chromosomes in the Uzifly, Exorista bombycis, (Diptera: Tachinidae)
}

\author{
H. B. Manjunatha and H. P. Puttaraju \\ Department of Sericulture, Bangalore University, Bangalore 560009 , India
}

Accepted January 23, 1992

The 'Uzifly' a well known endoparasite of the silkworm Bombyx mori is being known by different names viz., Trycholyga bombycis, Trycholyga sorbillans, Exorista sorbillans, Exorista bombycis. While giving an extensive review of this tachinid fly, Siddappaji and Channabasavanna (1990) reported that Exorista parasitoid of Bombyx mori is to be called, Exorista bombycis (Louis). The taxonomic identity of the fly is mainly based on some external morphology and on its host specificity. But these characters never always reveal close relationship, at least among a few taxa. Recent investigations for the last few decades have demonstarted that relationship between species, genera and families could be strongly based on information from cytology. In view of this, chromosome analysis of this economically important fly has been made which helps not only in its identification but also to compare the karyotype of this species with the allied species to know the cytological nearness.

\section{Materials and methods}

Full grown parasitic Uzi maggots were collected soon after their emergence from the infested silkworm cocoon at the Cocoon Market of Bangalore and allowed them to metamorphose into adults in the wire mesh netted cages. The adults were provided with $8 \%$ glucose wetted in cotton and allowed them for mating. About a day after their emergence, few live fourth instar silkworm larvae were kept in the cages to facilitate flies to oviposit on them and to continue their endoparasitic life (Datta and Mukherjee 1978). Third instar maggots which were removed out by dissecting the silkworm larvae as well as their pupal stage were utilized for dissection. Their brain and imaginary disc cells were used for chromosome preparation following the methods of Bedo (1980) and Puttaraju and Chowdaiah (1984). The Leitz microscope supplemented with Wild camera regulated by MPS-45 photoautomat was used for both observations and photomicrography. Morphometric measurements of well spread metaphase chromosomes were made with the help of drawings outlined using camera lucida at a magnification of $1000 \times$. The idiograms were prepared by the conventional method.

The chromosome analysis were made according to the method described by Boyes and Wilkes (1953) and Sharma and Talukder (1974). With regard to total complement length, the true total complement length represents for females and the corrected total complement length represents for males. This is because the individuals carrying heteromorphic pair (XY), double the length of the X-chromosome is substituted for the sum of the length of the heteromorphic partners, so that all calculations for males and females are in a comparable basis.

\section{Results}

An analysis of 20 well spread metaphase plates from each sex of Exorista bombycis reveals that the chromosome number confirmed to be $2 n=12$ (Puttaraju and Chowdaiah 1984, Manjunatha and Puttaraju 1992). The karyotype consists of 5 pairs of submetacentric autosomes 
in a graded series. The X-chromosome is the smallest element and is acrocentric (1 to $1.15 \mu \mathrm{m})$. The $\mathrm{Y}$-chromosome is longer than the $\mathrm{X}$-chromosome and is submetacentric ( 2.42 to $3.36 \mu \mathrm{m})$. Further the sex chromosomes are homomorphic in female and are heteromorphic in male.

The total complements length ranged from 62.36 to $80.22 \mu \mathrm{m}$ and averaged $68.82 \mu \mathrm{m}$ in male. In female it ranged from $61.69 \mu \mathrm{m}$ to $83.93 \mu \mathrm{m}$ with an average of $68.28 \mu \mathrm{m}$. The karyotype is illustrated in Figs. 1, 2. The details of analysis are shown in Table 1 and Fig. 3. The comparative analysis of somatic complements at mitotic metaphase from male and female larvae (taking the X-chromosome of each male twice) revealed no differences in the results of chromosome analysis between the two sexes.

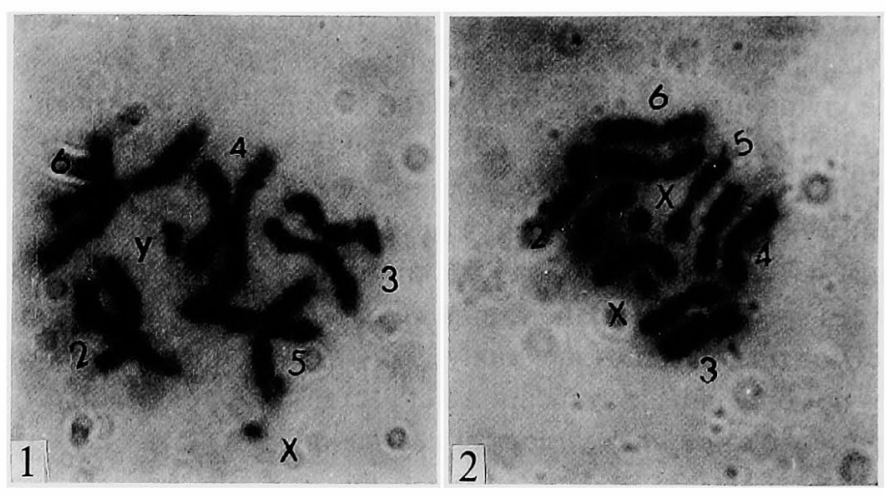

Fig. 1. Male karyotype of Exorista bombycis.

Fig. 2. Female karyotype of Exorista bombycis.

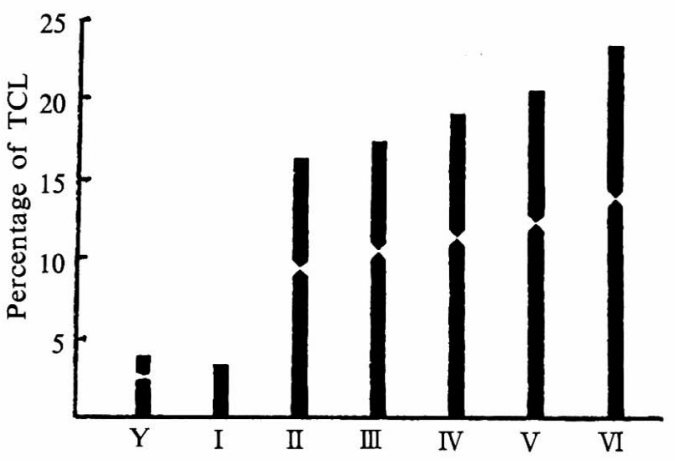

Fig. 3. Idiograms of the somatic complements of Exorista bombycis.

The sex pair which is also considered as pair I can be easily distinguished regularly on the basis of their relative lengths. In male the Y-chromosome is longer than the $\mathrm{X}$-chromosome. There is no overlap between the sex chromosome and the autosomes. They are comparatively distinct in their length. Pair II is shorter than other autosomal pairs but the arm ratio slightly overlap with pair III. However, since they differ in length no appreciable difficulty was encountered in distinguishing them. Though, pair IV and V have higher arm ratio than other pairs, they showed a slight overlap between them. But, these pairs can also be distinguished based on their relative length. Pair VI has more relatively longer length than other pairs and the arm ratio little lower than pair IV and V and much higher than pair II and III. The average arm ratio for pair II to VI showed 1.41 in male and 1.45 in female.

The centromeric index showed similar nature in all the chromosome pair from II to VI and averaged 0.41. Based on the morphological index each chromosome pair from II to VI are distinguished as they are in increasing order of length from pair II to pair VI.

\section{Discussion}

The present paper provides detailed description of somatic complements of Exorista 


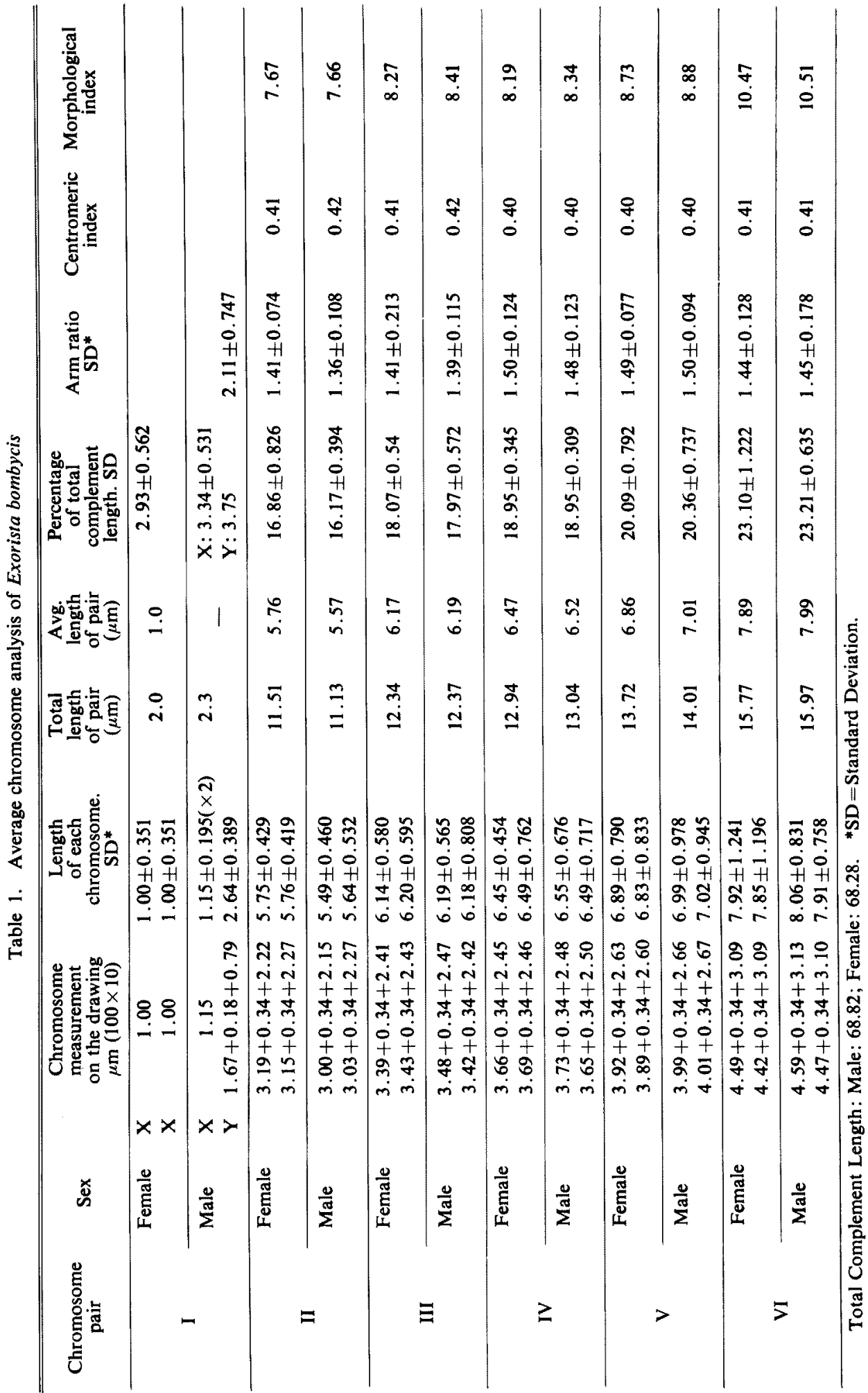


bombycis which helps to compare with the other members of the higher Diptera described by earlier workers.

The individual chromosomal pairs of this taxon can be identified (Table 1) with ease as all the autosomal pairs differ markedly in their relative length. The identification of sex chromosomes is unequivocal which acts as a marker chromosome because of their relatively smaller size. In male, the $\mathrm{Y}$-chromosome is longer than $\mathrm{X}$-chromosome with certainity and therefore this Tachinid insect is unique in this respect. In contrasting with the earlier (Puttaraju and Chowdaiah 1984) arrangement of chromosomes of this taxon in descending order based on their relative length, the chromosomes in the present paper are arranged in ascending order after placing the sex chromosome pair as I, with a view to compare the karyotype of this taxon with those of other higher Dipterans.

Table 2. Comparison of the present somatic chromosome complement of Exorista bombycis with those of other members of the family Tachinidae studied earlier by Boyes and Wilkes (1953)

\begin{tabular}{|c|c|c|c|c|c|c|c|}
\hline \multirow{3}{*}{$\begin{array}{l}\text { S1. } \\
\text { No. }\end{array}$} & \multirow{3}{*}{ Species } & \multicolumn{4}{|c|}{ Sex chromosomes } & \multirow{3}{*}{$\begin{array}{l}\text { Avg. } \\
\text { arm ratio }\end{array}$} & \multirow{3}{*}{$\begin{array}{c}\text { Avg. } \\
\mathrm{TCL}(\mu \mathrm{m}) \\
\mathrm{I}-\mathrm{VI}\end{array}$} \\
\hline & & \multicolumn{2}{|c|}{$\mathbf{Y}$} & \multicolumn{2}{|c|}{$I(X)$} & & \\
\hline & & $\% \mathrm{TCL}$ & Arm ratio & $\% \mathrm{TCL}$ & Arm ratio & & \\
\hline 1. & Aplomya caesar & 3.5 & 1.00 & 11.3. & 1.68 & 1.70 & 57.7 \\
\hline & Aplomya mitis & 4.0 & 1.25 & 9.1 & 1.51 & 1.72 & 45.5 \\
\hline & Ceracia dentata & 5.6 & 1.25 & 6.2 & 2.61 & 1.53 & 52.7 \\
\hline 4. & Ceromasia auricaudata & 4.4 & 1.22 & 6.0 & 1.67 & 1.23 & 54.8 \\
\hline & Drino bohemica & 3.8 & 1.21 & 7.4 & 2.09 & 1.22 & 63.7 \\
\hline & Eumea westermanni & - & - & 5.9 & 2.17 & 1.28 & 50.8 \\
\hline & Exorista bombycis & 3.7 & 2.11 & 3.1 & - & 1.43 & 68.5 \\
\hline 8. & Lydella grisescens & 18.4 & 1.24 & 19.8 & 1.25 & 1.22 & 69.8 \\
\hline 9. & Madremyia saundersii & 4.3 & 1.00 & 12.9 & 1.43 & 1.22 & 52.8 \\
\hline 10. & Mericia ampelus & 3.6 & - & 7.0 & 1.12 & 1.35 & 42.7 \\
\hline 11. & Nemorilla pyste & - & - & 13.0 & 1.18 & 1.21 & 55.4 \\
\hline 12. & Neophorocera hamata & 3.4 & 1.10 & 4.8 & 1.41 & 1.60 & 68.3 \\
\hline 13. & Omotoma fumiferance & 8.7 & 2.25 & 10.9 & 3.97 & 1.35 & 64.3 \\
\hline 14. & Phryxe pecosensis & 4.1 & 1.13 & 6.6 & 2.60 & 1.17 & 48.9 \\
\hline 15. & Spathimeigenia sp. & 4.4 & 1.17 & 6.0 & 2.80 & 1.61 & 53.8 \\
\hline 16. & Winthemia datanae & - & - & 31.0 & 1.13 & 1.34 & 54.0 \\
\hline 17. & Winthemia occidentis & 6.0 & 2.88 & 16.2 & 7.53 & 1.25 & 64.0 \\
\hline
\end{tabular}

$\mathbf{T C L}=$ Total complement length

The comparative study of higher Dipterans like Tachinids (Boyes and Wilkes 1953), Muscids (Boyes et al. 1964), Sarcophagids (Boyes 1953), and Calliphorids (Boyes 1961), revealed two aspects with reference to their karyotypes. They are (1) the chromosome complements and (2) the nature of the autosomes and sex chromosomes.

Interestingly in all the cytologically known species of the aforesaid families, the usual diploid number is 12 with a deviation in some species of Muscids wherein the chromosome number is reduced to 10 and in one species of Sarcophagid, Pseudosarcophag affinis, the somatic chromosome number is stated to be 19 or 20. Of all the species of higher Dipterans so far studied, Pseudosarcophag affinis is the only species having the highest number of chromosomes with all acrocentric except one pair which is submetacentric (9th pair, Boyes 1953). A karyotype with all acrocentric chromosomes is generally considered as a karyotype of an ancestral form. Based on this, the karyotype of Pseudosarcophag affinis can be considered as an ancestral one though there is a submetacentric pair which may be a secondary feature (i.e. pericentric inversion). Since the diploid number is 19 or 20 in Pseudosarcophag affinis, a 
more generalised hypothetical karyotype may be conceived. So this hypothetical form may be having 20 acrocentric chromosomes which may be the progenitor of other species with structural changes. The nature of the autosomes in most of the cases support this view as they are either metacentric or submetacentric or a combination of both. Such chromosomes, can only be derived by translocations.

Even the sex chromosomes are in general acrocentric in nature with larger $\mathrm{X}$ and smaller $Y$. Exceptionally to this "general rule", two species of Tachinidae show some variations (Table 2). Boyes and Wilkes (1953) reported that the X-chromosome of Winthemia species is larger than the largest autosome and therefore suggested to create a separate group. The present study demonstrates that the Y-chromosome of Exorista bombycis is larger than the Xchromosome which is unique in this respect and its inclusion in the family Tachinidae is enigmatic specially because of the contrasting feature of size and morph.

The variations in the autosomal complement and sex chromosomes are of great significance in the evolutionary cytogenetics. Further, the diversity in the size and morphology of the sex chromosomes seems to indicate that they have an independent evolutionary history.

It should be emphatically stated that the present analysis of somatic chromsomes of $E x$ orista bombycis will certainly facilitate systematists who have encountered considerable difficulty in naming this Tachinid species, and those who are evolving genetic control methods to eradicate this economically important pest.

\section{Summary}

A detail analysis of somatic chromosomes from the brain and imaginary disc cells of the Uzifly, Exorista bombycis a parasitoid of the mulberry silkworm Bombyx mori (Lepidoptera: Bombycidae) is presented. The karyotype is established to have 5 pairs of submetacentric autosomes in a graded series and a pair of sex chromsomes which are homomorphic in female and heteromorphic in male. The acrocentric $X$-chromosome is the smallest element and the $\mathrm{Y}$ is submetacentric and is larger than the $\mathrm{X}$-chromosome. This is unique to this species. The karyotype of this species is compared with those of other cytologically known Dipterans and discussed.

\section{Acknowledgement}

The authors sincerely thank to Prof. N. V. Ashwathanarayana Dept. of Zoology, University of Mysore, Mysore, for critically going through the manuscript and giving suggestions.

\section{References}

Bedo, D. G. 1980. C, Q and $\mathrm{H}$ banding in the analysis of $\mathrm{Y}$ chromosome rearrangements in Lucia cuprina (Wiede). (Diptera: Calliphoridae). Chromosoma (Berl.) 77: 299-308.

Boyes, J. W. 1953. Somatic chromosomes of higher Diptera: II-Differentiation of Sarcophagid species. Can. J. Zool. 31 : 561-576.

- 1961. Somatic chromosomes of higher Diptera: V-Interspecific and intraspecific variation in the Calliphoridae. Can. J. Zool. 39: 549-569.

-, Correy, M. J. and Paterson, H. E. 1964. Somatic chromosomes of higher Diptera: IX-karyotype of some Muscid species. Can. J. Zool. 42: 1025-1036.

- and Wilkes, A. 1953. Somatic chromosomes of higher Diptera: I-Differentiation of tachinid parasites. Can. J. Zool. 31: 125-165.

Datta, R. K. and Mukherjee, P. K. 1978. Life history of Trycholyga bombycis (Diptera: Tachinidae) a parasite of Bombyx mori (Lepidoptera: Bombycidae). Ann. Entomol. Soc. America. Vol. 75(5): 767-770.

Manjunatha, H. B. and Puttaraju, H. P. 1992. Preliminary studies of chromosomal behaviour during sper- 
matogenesis in Uzi fly Exorista sorbillans (Diptera: Tachinidae). In: G. K. Manna and U. Sinha, (Eds.), Perspectives in Cytology \& Genetics. Vol. VII (In press).

Puttaraju, H. P. and Chowdaiah, B. N. 1984. Cytological studies of the Uzifly, Tricholyga bombycis Beck. (Diptera: Tachinide). Sericologia 24(4): 519-524.

Sharma, A. and Talukder, G. 1974. Laboratory procedures in human genetics. Vol. I-chromosome methodology: 134-135.

Siddappaji, C. and Channabasavanna, G. P. 1990. The Indian Uzifly, Exorista bombycis. A parasitoid of the mulberry silkworm. Indian J. Seri. Vol. 29(1): 119-137. 